Da sintaxe ao discurso: o jurídico, o político e a ética nos efeitos de sentido da/sobre a saúde pública no Brasil | 39

\title{
DA SINTAXE AO DISCURSO: O JURÍDICO, O POLÍTICO E A ÉTICA NOS EFEITOS DE SENTIDO DA/SOBRE A SAÚDE PÚBLICA NO BRASIL
}

Augusto Radde ${ }^{8}$

RESUMO: Neste texto, cuja base teórica é a Análise de Discurso francesa, realizo uma leitura acerca do político e do jurídico, entrelaçados pela ética, na constituição das significações do discurso jurídico - considerado como da saúde pública - a fim de contrastá-lo ao discurso sobre a saúde pública e perceber as contradições que emergem dessa confluência de saberes. Saliento o olhar especial que será dado ao artigo 196 da Constituição Federal de 1988, o qual abre a seção destinada à saúde, do qual recorto o início a fim de que seja realizada uma leitura: A saúde é um direito de todos e dever do Estado. A organização sintática desse enunciado aponta ao fato de que se estabelece um jogo entre falta e excesso, instaurado principalmente pelo uso do pronome todos. A partir de então, maneiras de lidar com o discurso jurídico vão delineando sentidos através de discursos sobre a saúde pública - produzindo efeitos de regularidade, os quais apontam diferentes modos de subjetivação a respeito do direito e do dever garantidos na lei da saúde pública, produzindo efeitos de sentido.

Palavras-chave: Sintaxe; Discurso; Saúde Pública; Ética; Efeitos de Sentido.

ABSTRACT: In this text, whose theoretical basis is the French Discourse Analysis, I present a interpretation about the political and the juridical, intertwined by the ethics, in the constitution of the juridical discourse considered from public health - in order to contrast it with the discourse about public health and perceive the contradictions that emerge from this confluence of knowledge. I emphasize the special attention that will be given to the article number 196 of the 1988 Federal Constitution, which opens the section addressed to health, from which I cut the beginning to propose a interpretation: Health is a right of all and a duty of the State. The

8 Doutorando em Letras pela Universidade Federal do Rio Grande do Sul (UFRGS). Bolsista CAPES, atua como pesquisador na área de Estudos da Linguagem e é membro do grupo de pesquisa Oficinas de Análise de Discurso: Conceitos em movimento (UFRGS). 
syntactic organization of this enunciate points to the fact that there is a movement between absence and excess, instated mostly by the use of the pronoun all. From this point on, ways of dealing with the juridical discourse are delineating meanings through discourses about public health - producing effects of regularities, which points to different ways of subjectivation about right and duty granted by the law of public health, producing effects of meaning.

Keywords: Syntax; Discourse; Public Health; Ethics; Effects of meaning.

\section{Introdução}

Neste trabalho, observo os efeitos de sentido que se regularizam na contemporaneidade a respeito da saúde pública no Brasil. Para tanto, considero, com Pêcheux (1988 [1975], p.263), que "o sentido existe exclusivamente nas relações de metáfora (realizadas em efeitos de substituição, paráfrases, formação de sinônimos), das quais certa formação discursiva vem a ser historicamente o lugar mais ou menos provisório". Destaco, ainda, a importância de se considerar que o discurso, em sua relação intrínseca com a língua, funciona como um processo e "estando os processos discursivos na fonte da produção dos efeitos de sentido, a língua constitui o lugar material onde se realizam esses efeitos de sentido. Esta materialidade específica da língua remete à ideia de "funcionamento" (no sentido saussuriano), por oposição à ideia de ‘função”" (PÊCHEUX, 2014 [1975], p. 171, grifo e aspas do autor).

Muito se diz atualmente sobre a saúde pública no Brasil. Discursos caracterizados como da saúde pública, bem como sobre, pela e contra a saúde pública, os quais produzem efeitos de sentidos que remetem ao jogo entre o dentro e o fora desse lugar. Realizo aqui, a partir dessa relação, uma leitura acerca do político e do jurídico, entrelaçados pela ética (INDURSKY, 2002), na constituição das significações do discurso jurídico - considerado como da saúde pública - a fim de contrastá-lo ao discurso sobre a saúde pública e perceber as contradições que emergem dessa confluência de saberes. Aponto desde já o olhar especial que será dado ao artigo 196 da Constituição Federal de 1988, o qual abre a seção destinada à saúde na parte que lhe cabe em tal documento, do qual recorto o início para abrir a próxima seção deste texto: A saúde é um direito de todos e dever do Estado. 
Da sintaxe ao discurso: o jurídico, o político e a ética nos efeitos de sentido da/sobre a saúde pública no Brasil | 41

A saúde é um direito de todos e dever do Estado: língua, sintaxe e efeito de sentidos

À saúde atribuem-se designações que a mantém fiel ao discurso médico e jurídico desde muito tempo. Falar em saúde sempre reclama algo que a ela se opõe diretamente, ou seja, enquanto construção discursiva, ela remete à qualidade de se estar bem fisicamente, com um corpo forte, saudável, normal, ao contrário da doença, a qual, inversamente, designa um corpo fisicamente frágil, doente, anormal. Essa designação de saúde, quando determinada pelo adjetivo pública, aponta mais uma estabilização de sentidos e, diante dela, somos levados a pensar em equidade no atendimento, na possibilidade de igualdade no acesso aos serviços de saúde, independente da condição social dos sujeitos. Tanto é verdade que o discurso jurídico organiza-se em torno dessa premissa e legisla dizendo que a saúde é um direito de todos.

Entretanto, é nessa regularidade, marcada linguisticamente por esse pronome, que podemos pensar a opacidade, já que o todos, no enunciado, produz um efeito de regularidade dos sentidos que joga entre o excesso e a falta. Ou seja: Essa marca linguística afeta-me a investigar porque funciona como um ponto de acesso ao discurso. $O$ excesso produzido na materialidade linguística pelo uso desse pronome indefinido reflete uma economia do sistema linguístico na tentativa de saturar o sentido, contudo aponta para uma falta que é da ordem da história. Essa designação na língua leva à pergunta sobre um aspecto que é do social. Ao ocupar a posição sintática de complemento nominal de direito no enunciado "Saúde é direito de todos e dever do Estado", esse pronome compõe uma construção que reclama a seguinte pergunta: Quem são os indivíduos afetados no social por esse direito à saúde, quem são todos?

Essa maneira de lidar com a língua configura o modo de considerá-la como um lugar de equívoco, de heterogeneidade, bem como de considerar que “(...) ela constitui igualmente substância, matéria possível para as fantasias [fantasmes], conjunto inconsistente de lugares para o desejo - a língua é, desse modo, aquilo que o inconsciente pratica, prestando-se a todos os jogos inimagináveis para que a verdade, no compasso das palavras, fale" (MILNER, 2012, p.22, destaque do autor). Essa verdade, convém salientar, não é aquela do senso comum, em oposição à mentira, mas aquilo que vem do inconsciente e insiste em penetrar por entre os espaços preenchidos pelas palavras, balançando a estrutura da língua e colocando em prova a sua transparência. 
Esse compasso das palavras no jogo apresentado pelo enunciado em análise reclama, para que se perceba os efeitos de sentido, a história. Por se tratar de uma questão amparada pelo discurso jurídico, a partir da legislação que assegurou o período de redemocratização do Brasil ${ }^{9}$, a saúde pública aparece como um recurso que oscila entre o direito e o dever, apontando o movimento inerente ao que é de ordem legal. Diferentemente da parte do discurso constitucional dedicada ao que não pode ser feito, responsável por conduzir as práticas sociais com base no dever do cidadão, o que se diz da saúde pública no texto referenciado é formulado fundamentalmente para amparar o direito do cidadão; entretanto, no funcionamento discursivo de ambos, há um entrelaçamento entre o jurídico e o político participando da produção dos efeitos de sentido. Voltarei a essa questão adiante, mas antes dou um salto de volta ao passado para tratar da língua e, particularmente, da sintaxe.

A questão da determinação em linguística aparece como aquilo que relaciona a posição dos elementos na organização sintática da frase, fazendo ressoar o que predominou no pensamento dos gramáticos a esse respeito. Arnauld e Lancelot (2001) apresentam uma leitura da Gramática de Port-Royal, a qual, ao seguir essa direção, entende a relação entre os substantivos e os adjetivos como uma oposição entre substâncias / coisas e modos das coisas / acidentes, respectivamente, de tal forma que os segundos dependeriam dos primeiros para existirem no discurso ${ }^{10}$. "Já que a substância é aquilo que subsiste por si mesmo, chamaram-se substantivos todos aqueles que subsistem por si mesmos no discurso, sem que tenham necessidade de outro nome, ainda que signifiquem acidentes”. E de forma totalmente inversa, “(...) foram chamados adjetivos mesmo aqueles que significam substâncias, quando por sua maneira de significar, devem estar juntos a outros nomes no discurso" (ARNAULD \& LANCELOT, 2001, p.32-33). Como podemos perceber, a distinção se dá a partir do que prevê a distribuição dos elementos por características de dependência em relação a outros elementos do discurso.

9 Refiro-me ao texto da Constituição da República Federativa do Brasil, de 1988.

${ }^{10}$ Essa concepção de discurso adotada pelas gramáticas, das clássicas às modernas, difere-se da que adotamos na Análise de Discurso, pois refere-se ao campo da fala, estando totalmente dependente da organização interna da língua e a mercê de um sujeito que o manipula. A nosso ver, discurso relaciona-se à língua de outra forma, visto que essa relação coloca em cena os processos os quais, em funcionamento, materializam-se na base linguística, afetados pelo exterior, que é responsável por abrigar a historicidade dos sentidos e a ideologia. 
Da sintaxe ao discurso: o jurídico, o político e a ética nos efeitos de sentido da/sobre a saúde pública no Brasil | 43

No caso do objeto em análise, num âmbito geral, o adjetivo pública funciona como um determinante linguístico do substantivo saúde, estabelecendo no discurso, pelo jogo das palavras na organização sintática, uma característica da saúde, a qual é assim determinada para caracterizar um tipo específico: a saúde oportunizada e garantida por lei a todos os cidadãos brasileiros. E essa determinação aparece no enunciado em tela através da formulação direito de todos, produzindo efeitos de sentido que vão na mesma direção, através de uma relação de paráfrase - noção que será retomada adiante a fim de que seja esclarecida a concepção discursiva em que me apoio para pensá-la na produção dos sentidos.

Essas relações, amparadas pela lógica que prevê uma relação entre as coisas do discurso e as coisas do pensamento, estabelecem uma maneira de lidar com a língua e, apesar de apontarem a uma exterioridade, limitam-se a restringir as significações ao sistema, interrompendo o percurso em direção a uma semântica a qual, efetivamente, coloque em tensão as coisas relativas ao que está dentro e as que dizem respeito ao que está fora da língua. Na mesma direção seguiram os estudos linguísticos, de cujos um dos expoentes é Chomsky e a sua gramática gerativa (GGT). Segundo o linguista, a dicotomia competência / desempenho marca as especificidades da língua, caracterizando sua existência sistemática.

A competência aponta o fato de que há uma estruturação sintática de conhecimento inato dos falantes, capaz de gerar sentenças adequadas às regras estipuladas para essas sentenças, o que as torna gramaticais, em oposição às sentenças geradas sem as propriedades adequadas a essas regras, portanto, agramaticais. Já o desempenho aponta o fato de que o falante possui a capacidade intuitiva de julgar adequadas ou inadequadas as sentenças de sua língua, de acordo com o as propriedades globais de um enunciado, o que lhe permite a possibilidade de aceitar ou rejeitar determinadas sentenças geradas na língua, conferindo ao desempenho a característica de aceitabilidade.

Em "Aspects" (1965), traduzida para o espanhol como "Aspectos de la teoria de la sintaxis", com base na dicotomia apresentada, Chomsky estabelece uma relação entre sintaxe e semântica no que se refere às fronteiras que as separam, a partir do que denominou de graus de gramaticalidade. Segundo o autor:

As orações que quebram regras de seleção podem ser, frequentemente, interpretadas 
metaforicamente (em particular, como personificações - cf. BLOOMFIELD, 1963 ) ou alusivamente de um a maneira ou de outra, se a elas é fornecido um contexto apropriado de maior ou menor complexidade. Quer dizer, essas orações são, ao que parece, interpretadas mediante uma analogia direta com orações bem formadas que observam as regras de seleção em questão ${ }^{11}$ (CHOMSKY, 1971 [1965], p.141).

Essa passagem segue o raciocínio do autor sobre as particularidades, os tipos de quebras de regra responsáveis por uma aberração que vem a produzir orações com maior ou menor grau de gramaticalidade. Para diferenciar de outras violações das regras estruturais de uma língua, é apresentada a célebre sentença colorless green ideas sleep furiosly (incolores ideias verdes dormem furiosamente). Para o autor, há aí um caso de violação das regras de seleção pelos traços sintáticos, a qual diz que algumas unidades lexicais não podem ser encaixadas na frase se não sustentarem a relação entre forma e sentido já estabelecida pela categoria dominante do ponto de vista da seleção. O substantivo, no caso.

Sobre essa sentença, o linguista postula que, apesar de não possibilitar uma leitura coerente, já que construída sem a possibilidade de um sentido claro, ela não deve ser considerada agramatical, tendo em vista que respeita a estruturação gramatical da língua. A colocação de adjetivos excludentes e de um verbo que não condiz com uma ação executada pelo sujeito designado por tal substantivo (ideas), torna a frase a-semântica sem que, contudo, perca seu traço de gramaticalidade, o que deixa clara a soberania dada à sintaxe em relação à semântica na teoria chomskyana. A aberração consistiria, desse modo, no que diz respeito ao sentido global do enunciado, portanto, à aceitabilidade, mantendo-se a sentença num alto grau de gramaticalidade.

\footnotetext{
${ }^{11}$ A tradução é minha. Transcrevo aqui o trecho original da versão em espanhol: Las oraciones que quebrantan reglas seleccionales pueden ser interpretadas, a menudo, metaforicamente (en particular, como personificaciones - cf. BLOOMFIELD, 1963 -) o alusivamente de uma manera o de outra, si se las provee de um contexto apropriado de más o menos complejidad. Es decir, estas oraciones son, a lo que parece, interpretadas mediante uma analogia directa com oraciones bien-formadas que observan las reglas seleccionales em cuestión.
} 
Da sintaxe ao discurso: o jurídico, o político e a ética nos efeitos de sentido da/sobre a saúde pública no Brasil | 45

Podemos ver nesse posicionamento a ideia de que haveria um sentido preexistente determinando e julgando o possível, com base em regras rígidas e excludentes, mesmo que reconheça a existência do agramatical na estrutura. Desse modo, não há na teoria chomskyana, contraditoriamente, um espaço para que pensemos e trabalhemos a subversão, o impossível que coexiste na sintaxe da língua, visto que se constitui “(...) em um modelo teórico que pensa a linguagem como 'órgão mental' e não-contraditória da língua e da sintaxe. A GGT apaga assim sua própria descoberta ao encobri-lo no espaço da normalidade biológica” (FERREIRA, 2000, p.88, grifos da autora). Logo, apesar de reconhecer o absurdo da língua - conforme a noção de agramatical -, o falante deve julgar aquilo que se revela da ordem do impossível e, portanto, não pertencente à língua.

Pensar na possibilidade de subversão permite, também, pensar que na estabilidade de um enunciado "perfeito", de acordo com as regras da língua, é possível haver pontos de acesso ao discursivo, ou seja, na aparente normalidade lógica da organização sintática, há pistas para que cheguemos aos sentidos na história, a partir da relação entre o que é interno e externo ao sistema. É o caso do enunciado o qual serve de título a esta seção e será analisado a seguir, a partir de uma leitura discursiva da sintaxe em sua relação com os efeitos de sentido. $O$ que vimos até agora não nos permite caminhar em direção aos efeitos, apenas reconhecer o diferente para exclui-lo do que na estrutura da língua é imaginariamente estabilizado.

\section{Sintaxe, Discurso e Efeitos de sentido}

Do ponto de vista da análise do discurso, a sintaxe constitui-se em uma ferramenta primordial para que pensemos nos efeitos de sentido. Ela faz uma mediação entre a forma e o conteúdo, pois possibilita que percebamos a relação entre a ordem ${ }^{12}$ da língua e a dos processos de enunciação, os quais determinam a fronteira entre o dito e o rejeitado / não dito no discurso através de enunciados concretos, conforme Pêcheux

12 Segundo Orlandi (1996), há uma diferença ente a organização e ordem da língua: enquanto a primeira diz respeito apenas aos aspectos internos ao sistema linguístico, a segunda faz referência à articulação entre a ordem da língua, enquanto sistema significante e a ordem da história, enquanto materialidade simbólica, considerando a afetação mútua entre elas. Para a autora, essa articulação deve ser observada pelo analista através de um lugar específico, denominado de ordem do discurso. 
e Fuchs (2010[1975]). Desse modo, ela organiza as relações entre as unidades da língua, as quais também são responsáveis pelos efeitos de sentidos percebidos em uma análise, diferentemente da concepção no modelo chomskyano. Há uma substituição, portanto, desse modelo que prevê a sintaxe "(...) como instância única de articulação entre forma e sentido, por outros, nos quais a articulação é apreendida em diferentes planos (morfológico, lexical, sintático, semântico-discursivo)" (FERREIRA, 2002, p.98-99).

Dessa forma, é dividindo espaço com outras instâncias de significação que a sintaxe contribui para a concepção discursiva de língua, já que todas as categorias do sistema linguístico podem, na materialidade de um enunciado, servir de pistas para que se chegue aos efeitos de sentido na história. É nesse sentido que Pêcheux e Fuchs (2014[1975], p. 176) nos esclarecem sobre as articulações entre os mecanismos sintáticos e os processos de enunciação:

Antes de mais nada, o léxico não pode ser considerado como um 'estoque de unidades lexicais', simples lista de morfemas sem conexão com a sintaxe, mas, pelo contrário, como um conjunto estruturado de elementos articulados sobre a sintaxe. Em segundo lugar, a sintaxe não constitui mais o domínio neutro de regras puramente formais, mas o modo de organização (próprio a uma determinada língua) dos traços das referências enunciativas. (destaque dos autores)

Em outro texto, o qual Pêcheux escreve com Gadet (2004 [1981]), a questão da sintaxe é retomada para apontar em que a leitura de Chomsky deixou escapar o que viu de fundamental, qual seja a relação entre o possível e o impossível da língua. De acordo com os autores, a cegueira do linguista sobre a discursividade não lhe permitiu avançar na direção de um mundo semanticamente desestabilizado, onde o sentido não preexistiria comandando de fora as decisões dos falantes sobre o que deveria ou não pertencer à língua. A citação que segue esclarece bastante essa virada de concepção a qual prevê a intervenção de sequências exteriores e independentes, existentes no interdiscurso - lugar de 
Da sintaxe ao discurso: o jurídico, o político e a ética nos efeitos de sentido da/sobre a saúde pública no Brasil | 47 saturação dos sentidos (PÊCHEUX, 1988) -, produzindo efeitos na constituição dos sentidos de uma sequência dada:

Essa conversão teórica, levando em conta a existência histórica das 'materialidades discursivas', desloca ao mesmo tempo a questão do sujeito e a dos dados, já que, além da análise sintática da sequência, ela tende a substituir a interpretação semântica (sobrecarregada de pressupostos lógicojurídicos, em que a semântica repete as categorias do direto, macaqueando-as), por uma prática de interrogação dos textos referidos à sua posição em um campo histórico (GADET \& PECHEUX, 2004[1982], p. 158, aspas dos autores).

Henry (1990), em um texto que trata das construções relativas em sua relação com a determinação na concepção discursiva, problematiza o exposto pela gramática de Pot-Royal, a partir dos autores supracitados, a fim de mostrar que a questão da determinação linguística torna-se ineficiente para tratar dos efeitos de sentidos os quais derivam não só da língua mas das relações com a ideologia, também responsável pelo que é dito e não dito na concretude do discurso. Para tanto, o autor retoma Milner e Chomsky ${ }^{13}$, no que eles avançaram em relação à gramática clássica, ao trazer aspectos como referência e contexto, bem como na limitação teórica de ambos, para chegar à conclusão de que a autonomia da língua é, de fato, relativa.

A referência não pode estar subordinada à articulação entre sintaxe da língua e o pensamento do mundo exterior, permitindo escolhas ligadas à semântica de um mundo normal, mas sim relacionada aos processos de determinação sócio-históricos, concepção com a qual a noção de substituição, a partir das relações de paráfrase, é mais condizente. A autonomia referencial característica de algumas unidades lexicais em comparação a outras unidades, seja em relação à designação de

13 As obras dos autores, mencionadas por Paul Henry, são Arguments Linguistiques (1973) e Aspects (1965), respectivamente. Esta última também consultada e citada por mim neste trabalho. 
seres correspondentes no mundo das coisas - como no caso dos substantivos em Chomsky -, ou em relação à referência contextual a qual permite que alguns nomes de qualidade sejam independentes dos atos de enunciação e outros não - como no caso dos adjetivos em Milner -, perde seu valor explicativo.

Segundo o autor, isso se dá devido à intervenção do contexto em que as unidades aparecem, o que faz da referencialidade uma noção problemática, “(...) já que ao mesmo tempo ela coloca problemas teóricos sérios e se é conduzido a considerar o caráter referencial ou não referencial de uma unidade não como uma característica intrínseca desta unidade, mas como um efeito de sentido onde intervêm conjuntamente a sintaxe e fatores semânticos" (HENRY, 1990, p. 51). Eu diria, ainda, que se colocam fatores da ordem do discurso, em sua relação com a ideologia e com a historicidade dos sentidos.

Ao avançar seu raciocínio, ele problematiza a questão da substituição de unidades, independentemente dos graus de sinonímia, para concluir que é pela possibilidade de substituir um termo por outro que a questão da referencialidade deve ser posta, ou seja: os efeitos de sentido não surgem da independência das unidades, mas das relações estabelecidas entre elas. "Em outros termos, seria a substitubilidade da unidade que constituiria o objeto do discurso em objeto exterior ao discurso, precisamente porque ele é susceptível de aí figurar por formas diferentes daquela que o representa sem que o sentido do discurso seja modificado." (Idem, p.52) Passo agora a problematizar a questão da determinação sob o viés discursivo, para em seguida retomar as questões do político e do jurídico na observação dos efeitos de sentido...

\section{Sobre a Determinação Discursiva: uma análise}

Em que pese o exposto acima, ainda com Henry (1990), compartilho da ideia de que seja impossível "(...) designar qualquer coisa senão através de unidades que podem ser substituídas por outras expressões numa paráfrase"(p.52), entendendo-a, sob a ótica discursiva, como responsável pelo fato de o sentido constituir-se como um efeito, bem como pelo fato de que fatores sócio-históricos, abrigados na exterioridade do discurso, não cessam de se materializar na estrutura sintática da língua. Vejamos como Pêcheux e Fuchs nos esclarecem esse entrelaçamento:

Queremos dizer que, para nós, a produção de sentido é estritamente indissociável da 
Da sintaxe ao discurso: o jurídico, o político e a ética nos efeitos de sentido da/sobre a saúde pública no Brasil | 49 relação de paráfrase entre sequências tais que a família parafrástica dessas sequências constitui o que se poderia chamar de "matriz do sentido". Isto equivale a dizer que é a partir da relação no interior desta família que se constitui o efeito de sentido, assim como a relação a um referente que implique este efeito (FUCHS \& PECHEUX, 2014[1975], p166-67).

Por esse caminho, para que o discurso seja produzido, a articulação entre formações ideológicas e discursivas é apagada para o sujeito, de maneira que a relação de sentido entre o seu dizer, o dizer de outra posição sujeito no interior da mesma formação discursiva e/ou o dizer de uma posição sujeito determinada por outra formação discursiva, cuja discursividade lhe serviu de matéria, é por ele esquecida. Esse movimento de retorno entre sequências discursivas, materializado nas relações de paráfrase, dá origem ao sentido e o constitui enquanto efeito, isto é: atesta o fato de que nada está pronto e a correspondência entre a linguagem e o pensamento está longe de ser perfeita, sem falhas ou controlada pelo sujeito.

Olhemos para o funcionamento da sequência mencionada acima:

Sd1 - A saúde é direito de todos e dever do Estado, garantido mediante políticas sociais e econômicas que visem à redução do risco de doença e de outros agravos e ao acesso universal e igualitário às ações e serviços para sua promoção, proteção e recuperação.

Como disse no início deste texto, o trecho em destaque nessa sequência constitui o objeto por ora em análise. Para tanto, o trago de onde foi retirado: do artigo completo que abre a seção dedicada à legislação específica sobre saúde da Constituição Federal.

Observando a organização sintática dessa parte em destaque na sequência, percebemos duas determinações linguísticas saturando substantivos na primeira oração: uma responsável por determinar o termo saúde, em forma de predicado nominal que, através de um predicativo, funciona como seu qualificador, sob o esquema $\mathrm{N}$ é _-_- (direito de todos). E outra responsável por determinar, no interior desse predicativo, o termo direito, na forma de um complemento nominal, sob o esquema $\mathrm{N}$ de __- (de todos). Como podemos ver, estou reduzindo ainda mais a 
sequência, com foco na parte que diz respeito à saúde como direito, por considerá-la como suficiente para este momento da análise.

Como já mencionado acima, a colocação do pronome todos na posição de determinante produz um efeito de saturação de sentido efeito comum ao uso de determinantes discursivos - representando na língua algo que está desse modo indeterminado no interdiscurso, mas que pode ser recuperado na história, ou seja: todos, na transparência de seu sentido de totalidade, de universalidade - termo que inclusive aparece na sequência sob a forma do adjetivo universal - torna-se opaco se observarmos que ele pode retomar, sob outro efeito de sentido, as minorias, as classes dominadas na luta de classes. Esse termo, ao saturar o sentido de direito, o faz para saturar também o sentido de saúde, através de uma relação de paráfrase a qual, no interior da Formação Discursiva (FD) da saúde, permite à posição sujeito plenamente identificada com essa matriz de sentido a reformulação - no nível da determinação discursiva através da substituição do adjetivo pública por tantos outros termos. Tal funcionamento existe a fim de manter o sentido sob o efeito de regularidade e, assim, dissimular sua determinação histórica, a qual abriga as contradições no que diz respeito ao acesso aos bens sociais.

Linguisticamente falando, todos não retoma referencialmente nenhum substantivo no contexto do enunciado, mas funciona pela substitubilidade, a qual faz referência àquilo que está fora, não dito neste enunciado. É preciso recorrer às políticas públicas de saúde direcionadas a grupos específicos e bem determinados historicamente no seio das práticas sociais, os quais possuem representatividade frente às desigualdades de direitos que afetam as relações de classe, na formação social capitalista. E, desse modo, percebemos a determinação discursiva como um efeito decorrente de “(...) sucessivas determinações que vão desde o nível linguístico, passam pelo fio do discurso, projetam-se no processo discursivo e afetam as propriedades do discurso" (INDURSKY, 2013[1997], p.312).

O que fica de relevante, por ora, é a percepção de que determinação e indeterminação funcionam mutuamente como maneiras de se perceber o funcionamento do discursivo na sistematicidade da língua. Nesse sentido, "um processo que aparentemente só constrói a especificidade do dizível acaba por instaurar, pelo recalcamento do que poderia ser dito, uma zona de indeterminação no interior do próprio processo discursivo. Ou seja, a indeterminação é fruto do processo de determinação" (Idem, p. 316, grifo meu). E essa relação entre o dito e o não dito, portanto, constitui os sentidos na 
Da sintaxe ao discurso: o jurídico, o político e a ética nos efeitos de sentido da/sobre a saúde pública no Brasil | 51

ótica discursiva. Agora retomo a teoria para, na sequência, voltar à análise...

\section{Sobre o Jurídico e o Político: outra análise}

Indursky (2002) apresenta uma relação importante para que visualizemos as tramas discursivas que se materializam na língua. É com base em seu estudo que trago o entrelaçamento entre o jurídico, o político e a ética para pensar os discursos da/sobre a saúde pública. De acordo com a autora, o político não se confunde com o discurso político, tampouco o jurídico com o discurso jurídico, da mesma forma que ambos podem funcionar articulados em diversos discursos a que estamos expostos.

$\bigcirc$ político estaria funcionando como representação das forças sociais nos discursos, funcionado em campos discursivos diversos, não restrito, portanto, ao discurso político, apesar de não permear qualquer discurso. $\bigcirc$ político, nesse sentido, é um trabalho de construção discursiva do social. De modo semelhante, o jurídico constitui um trabalho que está no social, penetrando em práticas e discursos que remetem ao imaginário social sobre o que é legal ou ilegal, a partir do que preconizam os discursos jurídicos, os quais, responsáveis por ditar as regras e as normas a serem seguidas pelos cidadãos - e pelo Estado -, funcionam no entremeio do direito e do dever. Através dessa perspectiva, recorto um trecho do texto de Indursky o qual considero fundamental ao propósito da análise do meu objeto:

[...] não se trata de afastar/negar o discurso jurídico, mas de captar os diferentes gestos de interpretação que a partir dele se produzem. Estes gestos de interpretação do texto legal, instaurados por sujeitos nãoespecialistas, tecem processos discursivos que vêem afetados pelo interdiscurso e que também podem ser recortados por diferentes formações discursivas (INDURSKY, 2002, p. 118).

Desse modo, o político pode estar presente no discurso jurídico da mesma forma que o jurídico, já que ambos colocam em cena os saberes emanentes do social. Essa questão permite uma interpretação sobre os efeitos de sentido que emergem da materialidade discursiva do discurso 
jurídico, bem como a constatação de que dizer sobre o que é legal ou segue, na prática, a legislação está ao alcance de todo e qualquer cidadão, mesmo os não especialistas no direito.

Com base no exposto, retorno à análise. Permaneço ainda com o mesmo recorte da sequência trazida, a fim de problematizá-la um pouco mais: A determinação discursiva já trabalhada na seção anterior aponta para um jogo de forças de diferentes posições sujeito, e até mesmo de diferentes formações discursivas, que convivem no enunciado. Através do pronome $\operatorname{todos}^{14}$, o qual determina, pela relação de paráfrases, a saúde pública como direito da população e dever do Estado, ressoam efeitos de sentidos que designam a questão da saúde pública por referência à igualdade e à desigualdade social simultaneamente - efeitos oriundos de diversas posições sujeito, de forma que as diferenças sócio-históricas são apagadas na dissimulação produzida pelo texto legal. Ou seja: da transparência do enunciado - o qual atinge um nivel de totalidade / generalização - produzida pelo jogo das palauras no léxico e na sintaxe da língua, emergem as minorias sociais, como o pobre, a mulher, o negro, o homossexual etc, verdadeiro alvo das políticas públicas.

Nesse sentido, no enunciado em análise podemos ver ressoarem a memória discursiva ${ }^{15}$, a qual aponta para uma dispersão de sentidos

14 Convém a referência ao texto de Pêcheux, de 1982, intitulado Delimitações, Inversões, deslocamentos, no qual o autor discorre sobre os efeitos de sentidos produzidos por discursos que se materializaram na língua e tenderam a apagar as barreiras que separam os imaginários sociais constituídos na passagem das grandes revoluções que marcam a história mundial. A seguinte passagem, a qual diz respeito à transição do Feudalismo ao Capitalismo (revolução francesa), ressoa diretamente no que entendo sobre o funcionamento do todos no discurso da saúde pública e, portanto, influencia a minha interpretação: A particularidade da revolução burguesa foi a de tender absorver as diferenças rompendo as barreiras: ela universalizou as relações jurídicas no momento em que se universalizava a circulação do dinheiro, das mercadorias... e dos trabalhadores livres.

${ }^{15} \mathrm{Na}$ análise de discurso consideramos a memória, para além do psicológico, como o mecanismo que permite aos saberes retornarem do interdiscurso na materialidade discursiva, de modo que possam ser repetidos, (re)significados ou contestados no ato de enunciação do sujeito do discurso. Em seguida, esses saberes retornam à região do interdiscurso para lá ficarem até que novamente sejam reclamados, para comporem discursivamente nova enunciação, a qual é entendida na $\mathrm{AD}$ como um ato que coloca o dito em relação ao não dito, a partir da determinação ideológica que interpela o sujeito no discurso através da 
Da sintaxe ao discurso: o jurídico, o político e a ética nos efeitos de sentido da/sobre a saúde pública no Brasil | 53 advindos de diferentes posições sujeito, ali mesmo onde a contenção visa estabilizar e regular o saber sobre saúde pública, designada como um direito de todos e, portanto, universal. Dito de outro modo: no discurso jurídico - considerado aqui como o discurso da saúde pública - as posições sujeitos se confrontam, abrindo espaço a diferentes designações nos mais diversos discursos sobre saúde pública, às mais diversas percepções sobre ela, o que permite ver a contradição inerente ao discurso, entrelaçado entre político e o jurídico. E, ainda, os discursos sobre desdobram-se nos mais diversos setores da sociedade, todos amparados pelo jurídico e pelo político, a partir de imaginários constituídos ideologicamente contra / a favor / pela / na saúde pública.

Conforme mencionado no início desta seção, convém trazer a ética no que ela contribui para os efeitos de sentido produzidos. Do modo como é entendida aqui, ainda com Indursky (2002), a ética é responsável por organizar a sociedade a partir da moral, a qual conduz as regulações do comportamento dos cidadãos, o que interfere na maneira como o político e o jurídico articulam-se no funcionamento das práticas e dos discursos no campo social. A moral é responsável por organizar e manter a ordem social. Intimamente ligada ao direito, assim como ele a moral sofre modificações ao longo do tempo, permitindo diferentes maneiras de lidar com as questões sociais, ou seja, são produzidas diferentes subjetivações históricas, a respeito, por exemplo, das leis.

Isso leva a autora à conclusão de que há várias éticas, sobre o que ela delineia dois tipos: a ética conservadora e a ética social. Sobre a primeira, podemos entendê-la como aquela cuja tendência é privilegiar os interesses individuais em detrimentos dos interesses das demais classes sociais, compreendendo a lei de modo mais fixo. Eu diria que tendendo sempre à reprodução. Já sobre a segunda, podemos entendê-la como aquela que abre espaço para o novo, para a transformação, isto é, pensá-la “(...) para referir o questionamento feito à moral que sustenta a imutabilidade da lei e dos direitos adquiridos. Em suma, quando passa-se a falar de direitos sociais em detrimento dos direitos individuais" (INDURSKY, 2002, p.119). Tal leitura exige que avancemos na análise, em direção a novos efeitos de sentido.

No que diz respeito ao discurso jurídico da saúde pública no Brasil, a legislação visa garantir a saúde através da criação do programa

formação discursiva a que ele se vincula. Através da noção de memória discursiva, conseguimos ver a relação intrínseca entre a língua e a história. 
Sistema Único de Saúde (SUS), criado para sanar os problemas de acesso a esse "bem", sob o discurso da promoção, prevenção e recuperação da saúde de todos. Por esse viés, os políticos legislaram pelos cidadãos comuns a partir de uma ética social, mas de um lugar específico - o do especialista responsável pela organização social - lugar o qual coincide com o de um perito em direitos e deveres sociais; vemos aí também um entrelaçamento entre os discursos político e jurídico, como legitimadores dos saberes na condução das práticas sociais. Acredito que por isso se tenha como resultado tanto conflito de interesses no campo social, de onde emergem, por um lado, discursos que vão ao encontro desse propósito, a favor do SUS, mas, por outro, discursos que divergem com base em uma ética conservadora, contra o SUS, os quais tendem a apagar, agora por outro caminho - oposto - a desigualdade, tornando invisíveis as minorias e a luta histórica por um exercício de cidadania equânime.

As sequências abaixo foram recortadas de discursos sobre a saúde pública os quais circularam durante o ano de 2016, disponibilizadas ao domínio público na internet. A primeira ( $\mathrm{Sd} 2)$ é composta de trechos do Manifesto em favor do SUS, redigido por profissionais da área da saúde em julho de 2016 e publicado no mesmo mês no site oficial do Centro Brasileiro de Estudos em Saúde (Cebes). A segunda ( $\mathrm{Sd} 3$ ) de enunciados referentes a falas públicas do então ministro da saúde, Ricardo Barros, realizadas durante o ano de 2016, reunidas pelas mídias jornalísticas do país, conforme serão apontadas em nota. Vejamos:

$\mathrm{Sd} 2^{16}$ - A liberdade, segurança, igualdade e solidariedade são valores que vieram para ficar; o direito à saúde é um deles e se concretizou por meio da criação do Sistema Único de Saúde (SUS) (...) O direito à saúde não permite o seu descumprimento e medidas fiscais e econômicas que reduzam a capacidade do Estado de garanti-lo, causando mortes, sofrimento e doenças são formas indiretas de sua asfixia (...) Ora, nenhum ajuste poderá ferir o direito a políticas sociais e econômicas de garantia do direito à saúde (art. 196) e na Constituição não pode haver antinomia jurídica.

$\mathrm{Sd} 3$ - Exames com resultados normais são desperdícios ${ }^{17}$ (...) É preciso rever o tamanho do SUS (...) Nós não vamos conseguir sustentar o nível de

\footnotetext{
${ }^{16}$ http://cebes.org.br/

${ }^{17}$ http://brasileiros.com.br/2017/04/cinco-declaracoes-muito-preocupantesministro-da-saude/
} 
Da sintaxe ao discurso: o jurídico, o político e a ética nos efeitos de sentido da/sobre a saúde pública no Brasil | 55

direitos que a constituição determina ${ }^{18}$ (...) O SUS é tudo para todos, ou tudo que está disponível no SUS para todos? (...) Por isso que eu falei: para de sonho, gente. A realidade é diferente do sonho. É fácil falar. ${ }^{19}$

As duas sequência referem-se a discursos que foram produzidos durante os trâmites da proposta de ementa constitucional que estabelece um teto de gastos públicos em recursos considerados primários e garantidos pela Constituição Federal, dentre eles, dentre eles os destinados à saúde pública. Tal proposta é conhecida pelos nomes de PEC 241 e PEC 55, os quais lhe foram atribuídos enquanto tramitava em votação na câmara dos deputados e no senado, respectivamente, antes de ser aprovada e incorporada à carta magna do Brasil. Desse modo, ambos pronunciamentos, reunidos nas sequências, resultam de reflexões a esse respeito, num âmbito geral, e à saúde pública, particularmente, o que nos permite perceber a relação como o artigo 196, já trabalhado aqui. Passo agora à leitura de cada um desses recortes, a fim de expô-los à opacidade, considerando de que modo o político e o jurídico articulam-se a partir de uma das éticas já mencionadas e produzindo efeitos de sentido sobre a saúde pública.

Em Sd2, é possível perceber, nos trechos em destaque, um jogo na sintaxe que remete claramente ao artigo da constituição responsável pela garantia do direito à saúde. Percebemos através desse excesso marcado na língua uma posição sujeito que se subjetiva a partir de uma relação de paráfrase a qual remete à matriz de sentidos determinante da formulação saúde é direito de todos e dever do Estado, produzindo um efeito de regularidade, caracterizado pela tentativa de manutenção do direito ao acesso universal à saúde garantido juridicamente. Estamos diante de um discurso militante, produzido por profissionais da área, por isso, de dentro da saúde pública, funcionando, desse modo, a favor da saúde pública, concretizada a partir da criação do SUS.

Entendo que esse efeito de regularidade segue na mesma direção do artigo 196, apresentando um posicionamento a respeito do texto legal fortemente sustentado por uma ética social, visto que baseia-se nos direitos sociais, em detrimento de interesses restritos a classes economicamente privilegiadas (as elites). O direito de todos é considerado sobretudo, pois é retomado a todo momento e está acima de qualquer reajuste de contas

${ }^{18}$ http://zh.clicrbs.com.br/rs/vida-e-estilo/noticia/2016/08/relembre-frasespolemicas-do-ministro-da-saude-7253457.html

${ }^{19} \mathrm{http}: / /$ www.bbc.com/portuguese/brasil-37932736 
realizados nos âmbitos da economia do país, como podemos perceber no último trecho da sequência. Estamos diante de um efeito de evidência sobre o que está sendo protegido, bem como contra quem se protege, ou seja, o direito incondicional, e constitucional, à saúde é protegido de qualquer intervenção política que o impeça de ser exercido.

Conforme a concepção de determinação aqui apresentada, os efeitos são produzidos a partir de escolhas lexicais, de substituições parafrásticas as quais, articuladas à sintaxe, permitem ver o ponto em que a língua encontra a história: "a sintaxe ao mesmo tempo indiferente e responsável” (Gadet e Pêcheux, 2004[1982], p.160). Escolhas como liberdade, segurança, igualdade e solidariedade apontam a uma direção de uma rede de sentidos sustentada por uma ética social e fazem emergir, pelo não dito, as diferenças e desigualdades históricas que ressoam no imaginário dos brasileiros na contemporaneidade. Diante disso, torna-se impossível ignorar "(...) que a língua é afetada pela luta de classes, na determinação dos termos, fórmulas, construções, sintagmas, estruturas de enunciados" (Idem, p. 159)

$\mathrm{O}$ que vemos em Sd3 é um funcionamento que leva o sentido em direção contrária, remetendo a uma posição sujeito determinada por uma matriz de sentido oposta, a qual organiza os saberes em uma formação discursiva antagônica. Apesar de o recorte em questão representar a fala do ministro da saúde, há um efeito de regularidade que o caracteriza como algo dito de fora do setor, o qual produz um discurso sobre a saúde pública cujos efeitos de sentido sustentam um posicionamento contra a saúde pública, questionando a garantia de que se tenha acesso universal a ela, conforme garante a constituição. Pondo em causa, desse modo, o que é preconizado sob a formulação do enunciado saúde é direito de todos e dever do Estado. Fica a pergunta: a partir de que concepção de ética o discurso jurídico é questionado?

As ações de prevenção, proteção e recuperação, preconizadas no que diz respeito ao acesso universal à saúde, são postas em xeque logo no início da sequência, quando os exames "com resultados normais" (podemos ler preventivos) são determinados pela designação desperdícios. A negação do dever do Estado em relação à saúde emerge diante das demandas do setor e sob a impossibilidade de sustentação econômica para que a ela se tenha acesso universal. Dessa forma, o SUS sofre uma descaracterização, o que produz um efeito de regularidade sobre a sua ineficácia. Ele é questionado, assim como a lei máxima que o determina, 
Da sintaxe ao discurso: o jurídico, o político e a ética nos efeitos de sentido da/sobre a saúde pública no Brasil | 57

de modo que o artigo 196 seja interpretado, por tabela, como um sonho, distante da realidade.

Diante dessa leitura, podemos inferir que esse questionamento é amparado por uma ética conservadora, pois, apesar de questionar a lei, não o faz no para manter a universalidade do direito à saúde, produzindo, assim, um efeito de sentido condizente com o modo de subjetivação característico de um lugar social específico: aquele que abriga um sujeito o qual coloca os interesses individuais acima dois sociais, a partir da justificativa de que, mesmo se todos não forem contemplados, o esforço em tirar o país da crise se faz necessário, ou seja, mesmo que grande parte da população sofra vendo seus direitos à saúde diminuídos, contraindo doenças e percebendo-se desamparada no que diz respeito à proteção e à recuperação, o corte nos gastos públicos se faz urgente.

O ponto alto de acesso ao discurso, a esse efeito de sentido contra a saúde pública, é materializado na língua quando o todos é questionado através de um jogo com o tudo, termo escolhido para substituir, por uma paráfrase discursiva, o dever do Estado em garantir o acesso universal à saúde. Nesse sentido, não é negado o direito de todos, mas ele sofre uma restrição, a qual é sustentada / justificada pela possibilidade de o Estado não dar conta das demandas sociais e a população ter que se contentar com o que é possível ser feito por todos.

Vale ressaltar que essa reformulação do enunciado constitucional em análise aponta para uma ressignificação não condizente com os sentidos abrigados pela formação discursiva antagônica. Essa paráfrase é produzida com base em saberes recuperados na dispersão do interdiscurso (lugar de saturação dos sentidos), os quais são formulados considerando o que pode e convém ser dito a partir dessa posição sujeito, sob determinação da formação discursiva que lhe dá abrigo. Podemos perceber, no efeito de regularidade produzido por essa sequência, que há um desequilíbrio entre a saúde como direito de todos e como dever do Estado, produzindo, ainda, um efeito de oposição ao SUS, cujas falhas são evidenciadas.

\section{Para encerrar}

Procurei empreender neste texto um gesto de interpretação sobre o que é produzido em termos de efeito de sentido na formulação de discursos contemporâneos referentes à saúde pública no Brasil. Posso dizer que, no funcionamento sintático da língua, podemos chegar à história, de modo que os efeitos de sentido sejam apreendidos e ponham 
a ver a contradição inerente ao discurso. Uma palavra por outra, na constituição de sentidos, reclama na análise que consideremos o primado da metáfora sobre o sentido (PÊCHEUX, 1988). Nesse sentido, o jogo de substituições parafrásticas posto em prática através da determinação discursiva permite que se visualize a relação entre o que é dito pela língua e o que, ao não ser dito, pode ser recuperado da história, nos sentidos dispersos e indeterminados no social.

Pude constatar, ainda, que o jurídico e político, entrelaçados pela ética, constituem os efeitos de sentidos nos discursos $\mathrm{da} / \mathrm{na} /$ pela e sobre/a favor/contra a saúde pública. Sentidos recortados de diferentes lugares, materializados pelo modo de subjetivação dos sujeitos e marcados na ordem da língua. As três sequências analisadas apontam para diferentes concepções a respeito da saúde pública no Brasil, mostrando de que forma a sua opacidade leva a sentidos que percorrem diferentes direções. Sob essa ótica, a ética que sustenta esses discursos aponta para o modo como esse tema vem sendo tratado atualmente, bem como por quais vias os sujeitos relacionam-se com o discurso jurídico. Desse modo, a tensão entre as classes emerge do social e materializa-se, dentre outras formas, na sintaxe da língua, funcionando no entremeio do direito e do dever, supostamente garantidos juridicamente.

\section{REFERÊNCIAS}

ARNAUlD, A.; LANCELOT, C. Gramática de Port-Royal ou gramática geral e razoada. 2. ed. São Paulo, SP. Martins Fontes, 2001.

CHOMSKY, N. (1965) Aspectos de la teoria de la sintaxis. Madri. Aguilar, 1971.

FERREIRA, M.C.L. Da ambiguidade ao equivoco: a resistência da língua nos limites da sintaxe e do discurso. Porto Alegre, RS. Editora da Universidade/UFRGS, 2000.

FUCHS, C.; PÊCHEUX, M. (1975) A propósito da análise automática do discurso: atualização e perspectivas. In: GADET, F; HAK, T. (Orgs.). Por uma análise automática do discurso: uma introdução à obra de Michel Pêcheux. 5. ed. Campinas, SP: Unicamp, 2014. p. 159-249.

GADET, F.; PECHEUX, M. (1981) A língua inatingível: o discurso na história da linguística. Campinas, Pontes, 2004. 
Da sintaxe ao discurso: o jurídico, o político e a ética nos efeitos de sentido da/sobre a saúde pública no Brasil | 59

HENRY, P. Construções Relativas e articulações discursivas. In: GERALDI, J.W.; ORLANDI, E.P. (orgs.) Caderno de Estudos Linguísticos 19 - O discurso e suas análises. Campinas, 1990, p.43-64.

INDURSKY, F. (1997) A fala dos quartéis e as outras vozes. 2. ed. Campinas, SP: Unicamp, 2013.

INDURSKY, F. O entrelaçamento entre o político, o jurídico e a ética no discurso do/sobre o MST: uma questão de lugar-fronteira. Revista da Anpoll, v.1, n.12, 2002, p. 111-131.

MILNER. J.C. O amor da lingua. Canpinas, SP. Editora da Unicamo, 2012.

PÊCHEUX, Michel (1975). Semântica e Discurso: uma crítica à afirmação do óbvio. Campinas: Ed. Unicamp, 1988.

Recebido em: 15/10/2018

Aceito em: 09/11/2018 